\title{
Nebulization of a bovine surfactant in cystic fibrosis: a pilot study
}

\author{
M. Griese, P. Bufler, J. Teller, D. Reinhardt
}

Nebulization of a bovine surfactant in cystic fibrosis: a pilot study. M. Griese, P. Bufler, J. Teller, D. Reinhardt. CERS Journals Ltd 1997.

ABSTRACT: Cystic fibrosis $(\mathrm{CF})$ is a lethal disorder which results in excessive airway secretions and in chronic inflammation of the airways. In vitro and in vivo studies have shown that a lack of surfactant results in the closure of the small airways. In this pilot study, we aimed to determine whether surfactant administered by aerosol might improve lung function on a short-term basis in patients with $C F$.

In a randomized, crossover double-blind pilot study, $120 \mathrm{mg}$ of a lipid-extracted bovine surfactant (Alveofact) or placebo was aerosolized to five young adult patients with $\mathrm{CF}$ over a period of $30 \mathrm{~min}$ for five consecutive days. The sample size had the power of $90 \%$ to detect an increase in forced expiratory volume in one second (FEV1) of $15 \%(p<0.05)$.

Jet nebulization of surfactant produced particles of which more than $75 \%$ were the respirable range $(<5 \mu \mathrm{m})$. The inhalations were well tolerated. No changes in serum antibody titres against the surfactant proteins-B and -C (SP-B/SP-C) were observed. No differences in FEV1 and forced vital capacity were found before, and 30 or $90 \mathrm{~min}$ after, the inhalation.

This pilot study shows no acute or short-term benefits of surfactant inhalation in young adults with cystic fibrosis. However, a beneficial effect of exogenous surfactant cannot be excluded before other reasons for a lack of effect, such as insufficient quantity delivered, inhomogeneous distribution or inhibition of the surfactant in the lungs, have been completely ruled out.

Eur Respir J 1997; 10: 1989-1994.
The Lung Research Group, Kinderpoliklinik, Ludwig-Maximilians University, Munich, Germany.

Correspondence: M. Griese

The Lung Research Group

Kinderpoliklinik

Ludwig-Maximilians University

Pettenkoferstr 8a

D-80336 Munich

Germany

Keywords: Small airways

surface activity

surfactant protein B

Received: December 31996

Accepted after revision July 11997

The project was supported by a grant from the Wilhelm Sander Stiftung (Gr 93.002.1/2).
Treatment of lung disease in cystic fibrosis (CF) is based mainly on the clearance of pathological airway secretions, antimicrobial therapy and anti-inflammatory approaches to halt the destruction of the small airways, which severely limits the expiratory airflow.

Pulmonary surfactant is necessary to prevent the alveoli from collapsing at end-expiration. Several synthetic and natural surfactant preparations have recently been successfully introduced to treat neonatal and acute respiratory distress syndrome (ARDS) [1, 2]. Increasing evidence suggests that surfactant is needed not only in the most terminal parts of the airways but also in the narrow section through which air is conducted to the alveoli [3-6]. In vitro and in vivo studies have shown that a lack of surfactant results in the closure of the small cylindrical airways. In addition to this deficiency, the presence of phospholipases, albumin or fibrinogen in the airways with inflammatory reactions, severely disrupts the functional ability of surfactant to keep the conducting airways open $[5,7]$. The biological surface activity of surfactant, which was isolated from bronchoalveolar lavages of patients with CF, was found to be severely impaired, levels of the major phospholipid, phosphatidylcholine, and of surfactant protein-A (SP-A) being reduced $[8,9]$.

Surfactant administered by aerosolization has previously been shown to result in a significant improvement in lung function in animal models of injury $[10,11]$ and in adult asthmatics with an acute attack [12]. In patients with ARDS, natural lipid-extracted surfactants may be effective [13, 14], whereas an artificial surfactant was ineffective [15]. Asthmatic children with chronic airflow obstruction also showed no benefit [16].

In this pilot study, we aimed to determine whether surfactant aerosolization produces a short-term improvement in lung function in patients with $\mathrm{CF}$ and airflow obstruction especially in the small airways.

\section{Materials and methods}

\section{Chemicals}

The surfactant used was a lipid-extracted, natural surfactant preparation (Alveofact; Thomae, Biberach, Germany) now routinely used for the treatment of infant (neonatal) respiratory distress syndrome (IRDS) [17]. Apart from phospholipids, it contains about 1.7\% SP-B [7]. Human SP-B-dimer (in 1-propanol/phosphate-buffered saline $\left.(1: 1), 4 \mathrm{mg} \cdot \mathrm{mL}^{-1}\right)$ was used as the standard and was a gift from W. Seeger (Gießen, Germany). The monoclonal antibody against SP-B was a gift from Y. Suzuki (Kyoto, Japan) [18].

\section{Lung function measurements}

Lung volumes were determined by body plethysmography and the He-dilution technique, CO transfer 
factor by the single breath technique, and forced expiratory variables by pneumotachographic measurements (Masterlab V 4.2; Jäger, Würzburg, Germany). The tests were performed according to the guidelines of the American Thoracic Society/European Respiratory Society (1993) [19].

\section{Nebulization of surfactant}

The surfactant (Alveofact) was adjusted to the phospholipid concentrations indicated and a final $\mathrm{NaCl}$ concentration of $0.9 \%$. A $2.4 \mathrm{~mL}$ volume was placed in the blinded reservoir of the jet nebulizer (IS-2; Pari, Starnberg, Germany), which was connected to a Pari IS-2 compressor. The nebulizer was activated during the inspiratory cycle in the in vitro studies by an electronic trigger impulse from the respiratory cycle machine, and in the in vivo studies by the patients themselves.

In the in vitro studies, Alveofact, at $50 \mathrm{mg}$ phospholipids. $\mathrm{mL}^{-1}$, was nebulized and the material recovered on a filter after $20 \mathrm{~min}$ and after an additional $10 \mathrm{~min}$, during which time the surfactant suspension was nebulized to dryness. The recovered material was lipid-extracted. Phospholipid composition was determined by high performance thin-layer chromatography, and comparison was made with control surfactant $(20 \mathrm{~min}$ at room temperature).

The respiratory cycle machine (Pari, Starnberg, Germany) emulates tidal breathing and was operated at a minute ventilation of $5 \mathrm{~L}$, using a respiratory frequency of 10 breaths $\cdot \mathrm{min}^{-1}$ and a tidal volume of $500 \mathrm{~mL}$. The nebulizer output was trapped on fibre glass filters or particle size was determined by laser light scattering in Master Sizer X 1.2 (Malvern Instruments, Herrsching, Germany). Alternatively, nebulizer output was delivered via a mouthpiece to the seated patient. The aerosol was generated and delivered solely during inspiration. At end-inspiration the breath was held briefly for 2-3 s. All inhalations by the patients were monitored to ensure compliance and to identify adverse effects.

\section{Subjects}

Five male patients with CF (aged $26 \pm 3$ yrs, range 19 $34 \mathrm{yrs}$ ) were studied. All had a positive test for sweat chloride and all were in a stable clinical condition, showing no change in antibiotic, bronchodilator, or corticosteroid therapy in the previous 4 weeks and no hospitalization for respiratory infection within the previous 6 weeks. All patients had Pseudomonas aeruginosa, and one patient also had Burkholderia cepacia in his sputum. The sputum was obtained by drying the mucus membranes of the mouth before expectoration in order to protect it from saliva. The study protocol was approved by the local Ethics Committee.

\section{Study design}

In the first part of the study, the maximum dose of surfactant, that could be delivered during a reasonable period of nebulization, and the properties of the surfactant were determined in vitro. In the second part of this study, the immediate ( 30 and $90 \mathrm{~min}$ ) and the shortterm effects ( 5 days) of surfactant nebulization on lung function were assessed in a study of randomized, dou- ble-blind, placebo-controlled, and crossover design. The evaluation of safety included physical examination, routine serum chemistry and haematological tests, urine analysis, the determination of hydrophobic surfactant protein antibodies and pulmonary function tests, before and after the study. Each patient included was routinely seen on an out-patient basis and had a stable clinical condition and lung function parameters, at 6 and 3 months and immediately before the start of the study.

After randomization, a basal lung function test was performed and either placebo $(0.9 \% \mathrm{NaCl})$ or surfactant (2.4 mL Alveofact (120 mg surfactant) in $0.9 \% \mathrm{NaCl})$ was administered as described above. The nebulization took approximately 20-25 min. Before, and $30 \mathrm{~min}$ and 90 min after starting each nebulization, lung function tests were performed. All subjects were studied at the same time of day. After 5 days of daily consecutive inhalations and after a washout period of 3-5 days, treatment was crossed over and the other compound was administered in the same way for another 5 days.

\section{Biochemical and biophysical analysis}

Sputum was collected three times a day throughout the study period and was weighted. Aliquots of sputum from each day were lipid-extracted [20], the lower phase was washed using the method of Folch et al. [21], and phospholipid content [22], and phospholipid species composition were determined [23]. Other aliquots were used to determine the SP-B content by a solid phase enzyme-linked immunosorbent assay (ELISA) [24]. The presence of serum antibodies directed against the surfactant proteins SP-B or SP-C was screened in serum samples taken before, and 2 weeks and 3 months after the study, using polyclonal antibodies which had previously been raised in rats against the hydrophobic proteins of the surfactant preparation (Alveofact) [25]. Surface tension was measured in a pulsating bubble surfactometer (Electronetics, Amerherst, NY, USA) at a phospholipid concentration of $3 \mathrm{mg} \cdot \mathrm{mL}^{-1}$ in $0.9 \%$ saline with $3 \mathrm{mM} \mathrm{CaCl}_{2}$.

\section{Statistical analysis}

Based on a standard deviation of $9 \%$ for FVC and $7 \%$ for FEV1 on repeated lung function testing during the previous 6 months, the sample size necessary to detect an increase in FEV1 by $15 \%$ and in FVC by $20 \%$ was calculated before starting the study. Setting a power of $90 \%$ and a significance level of $5 \%$, it was found that a minimum of five patients would be required in each group to demonstrate changes of this magnitude. To decrease variability between different subjects in a control and treatment group, a crossover design was chosen [26]. Data are presented as mean \pm SEM for $\mathrm{n}$ independent determinations. Comparisons were made by the t-test, and a $\mathrm{p}$-value of less than 0.05 was set as level of significance.

\section{Results}

\section{In vitro studies of surfactant nebulization}

Jet nebulization of the surfactant with the IS- 2 nebulizer resulted in a particle spectrum with more than $75 \%$ 
Table 1. - Effect of jet nebulization on phospholipid composition and surface activity of a bovine, lipid-extracted surfactant (Alveofact)

\begin{tabular}{|c|c|c|c|}
\hline & \multirow[t]{2}{*}{ Control } & \multicolumn{2}{|c|}{ Jet nebulization } \\
\hline & & $20 \mathrm{~min}$ & $30 \mathrm{~min}$ \\
\hline $\begin{array}{l}\text { Lysophosphatidylcholine } \\
\% \text { of total }\end{array}$ & $\begin{array}{c}2.8 \pm 0.3 \\
(\mathrm{n}=6)\end{array}$ & $\begin{array}{c}3.3 \pm 0.4 \\
(n=4)\end{array}$ & $\begin{array}{l}3.9 \pm 0.2 * \\
(\mathrm{n}=4)\end{array}$ \\
\hline rads $\mathrm{mN} \cdot \mathrm{m}^{-1}$ & $\begin{array}{c}52.2 \pm 4.9 \\
(\mathrm{n}=5)\end{array}$ & $\begin{array}{c}45.0 \pm 9.4 \\
(n=4)\end{array}$ & $\begin{array}{c}58.5 \pm 13.3 \\
(\mathrm{n}=4)\end{array}$ \\
\hline$\gamma \min \mathrm{mN} \cdot \mathrm{m}^{-1}$ & $\begin{array}{c}16.9 \pm 1.8 \\
(\mathrm{n}=5)\end{array}$ & $\begin{array}{c}16.8 \pm 3.3 \\
(n=4)\end{array}$ & $\begin{array}{l}15.4 \pm 5.1 \\
(\mathrm{n}=4)\end{array}$ \\
\hline
\end{tabular}

The relative content of lysophosphatidylcholine was significantly elevated after $30 \mathrm{~min}\left({ }^{*} \mathrm{p}<0.05\right)$. No significant changes were observed for the other phospholipids. Surface active properties measured at $3 \mathrm{mg} \cdot \mathrm{mL}^{-1}$ in a pulsating bubble surfactometer remained unchanged. Data are presented as mean \pm SEM from (n) experiments. yads: surface tension after absorption;

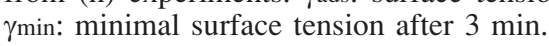

a)

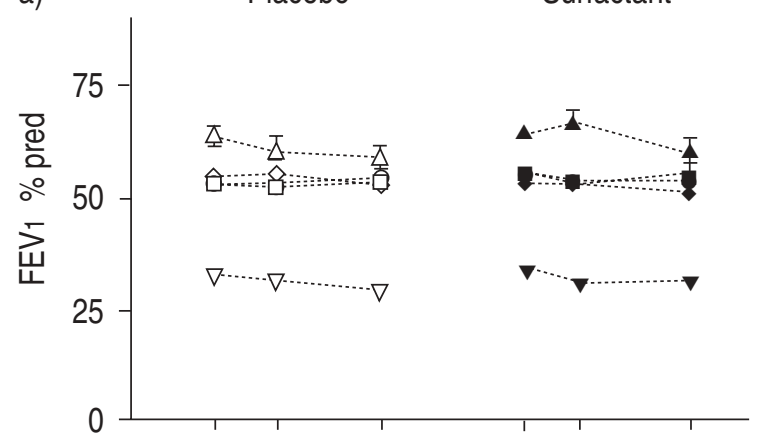

C)

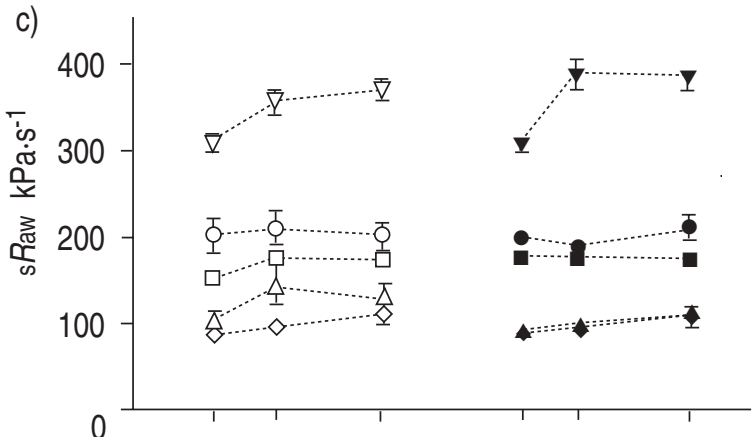

e)

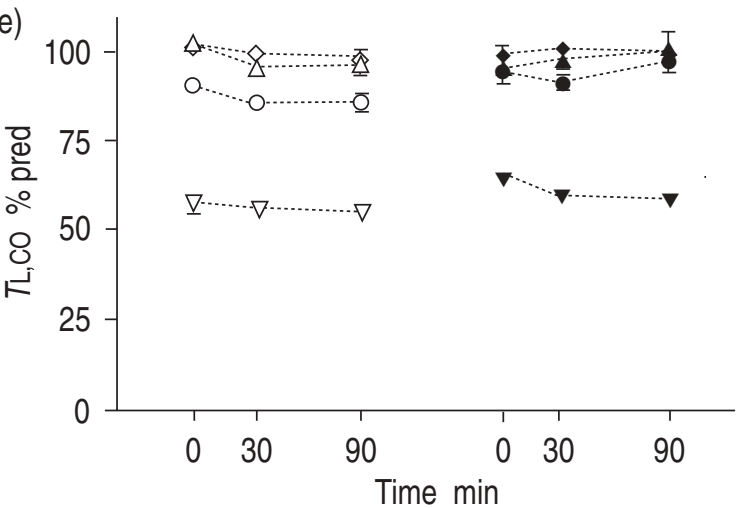

of the particles in the respirable size range, e.g. $<5 \mu \mathrm{m}$, and $20 \%$ were $<2 \mu \mathrm{m}$. Mass median diameter was 3.4 $\mu \mathrm{m}$, and the geometric standard deviation $1.7 \mu \mathrm{m}$. Foaming, which might interfere with nebulization, did not develop. Mass output increased linearly with the surfactant concentration $\left(3,6,12,25,50,100 \mathrm{mg} \cdot \mathrm{mL}^{-1}\right)$ used, whereas the relative recovery decreased (from about 35 to $18 \%$ ). Most of the losses were due to dried surfactant being trapped against the walls of the nebulizer. From these data, it can be estimated that from $2.4 \mathrm{~mL}$ of a 50 $\mathrm{mg} \cdot \mathrm{mL}^{-1}$ surfactant suspension about $20 \mathrm{mg}$ will be delivered to the mouth. Although some degradation of phosphatidylcholine occurred towards the end of the nebulization procedure, as indicated by an increased fraction of lysophosphatidylcholine (table 1), there was no loss of surface activity during nebulization (table 1 ). On the basis of these in vitro data, $50 \mathrm{mg} \cdot \mathrm{mL}^{-1}$ was selected as the optimal concentration for usage in further studies.

b)

Placebo

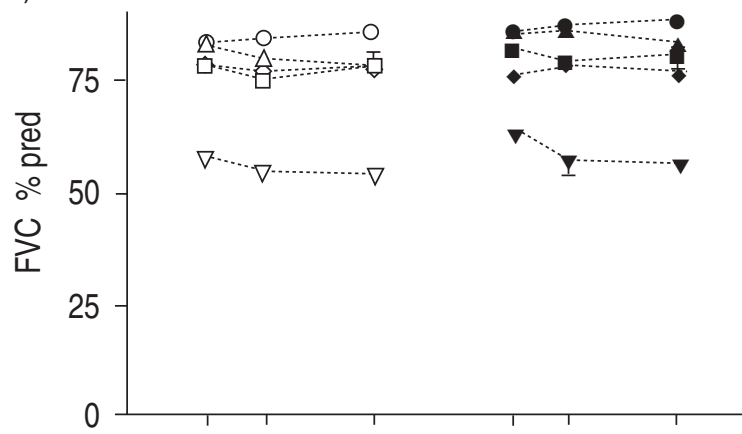

d)

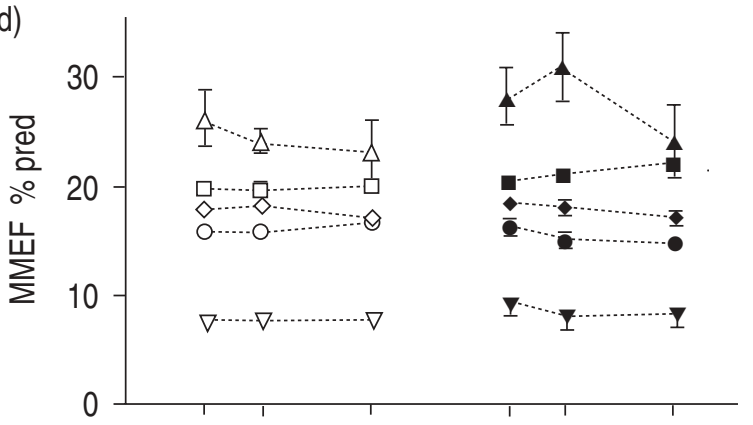

f)

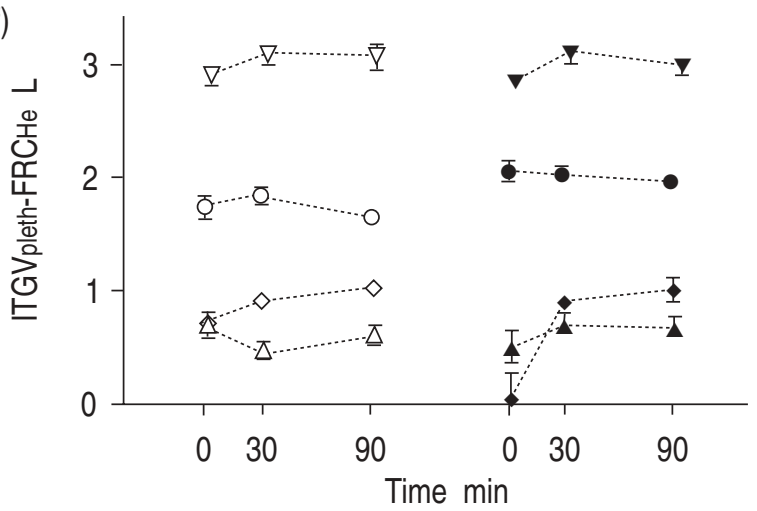

Fig. 1. - Effect of jet nebulization of a bovine, lipid-extracted natural surfactant (Alveofact, $120 \mathrm{mg}$ ) on lung function in five patients with cystic fibrosis $(\mathrm{CF})$. The patients inhaled placebo or surfactant in a study of double-blind design, on five consecutive days. After a washout period, the treatment was crossed over. a) Forced expiratory volume in one second (FEV1); b) forced vital capacity (FVC); c) specific airway resistance $(\mathrm{s} R \mathrm{aw})$; d) maximum midexpiratory flow rate between $75-25 \%$ of expired vital capacity (MMEF); e) transfer factor of the lung for carbon monoxide $(T \mathrm{~L}, \mathrm{CO})$; f) trapped gas, i.e. intrathoracic gas volume measured in the body plethysmograph (ITGVpleth) minus functional residual capacity measured by helium dilution (FRCHe). Data are presented as mean \pm sem for individual patients over the 5 days. Lung function tests were performed before and 30 and 90 min after the inhalations. \% pred: percentage of predicted value. 


\section{Discussion}

The inhalation of surfactant was well tolerated by patients who showed no adverse effects that could be attributed to the aerosolized administration of surfactant. One patient developed an exacerbation of the pulmonary infection 2 weeks after the completion of the surfactant inhalation period, this being treated with intravenous antibiotics. Whilst healthy normal adults do not usually have measurable serum antibody titres against the hydrophobic surfactant proteins (mainly against SPB) $(<1: 10)$ [25], all but one of the CF patients had elevated levels before therapy $(1: 20-1: 80)$. No significant changes in serum antibody titres were observed in the patients studied, when assessed at 2 weeks and at 3 months after surfactant therapy.

Aerosolized surfactant had no significant acute effect on FEV1 and FVC. This was observed on each day of aerosolization (fig. 1a and b). Moreover, there was no cumulative effect on these parameters during the shortterm treatment period of five consecutive days.

Additional secondary variables, which included: mean midexpiratory flow (MMEF), specific airway resistance (fig. 1c and d) and transfer factor of the lungs for carbon monoxide, and trapped gas (i.e. the difference between intrathoracic gas volume as measured by the body plethysmograph and functional residual capacity as measured by the helium dilution technique (ITGVpleth-FRCHe)), (fig. 1e and $\mathrm{f}$ ), and $\mathrm{O}_{2}$ saturation were not significantly altered by the inhalation of surfactant. In contrast, the inhalation of two puffs of salbutamol $(200 \mu \mathrm{g})$ resulted, in all patients, in a small but significant increase of FEV1 from 2.0 to $2.3 \mathrm{~L} \cdot \mathrm{s}^{-1}$, and a fall of specific airway resistance from 196 to $170 \%$ of predicted $(\mathrm{p}<0.05)$.

Sputum volume did not change with surfactant therapy. SP-B could not be determined in all the sputum samples due to nonspecific interferences. In those samples where reliable measurements could be made, the amount of SP-B recovered during the period of surfactant administration was increased in comparison to the placebo period. This indicates that some of the surfactant components delivered were expectorated later in association with the sputum (fig. 2).

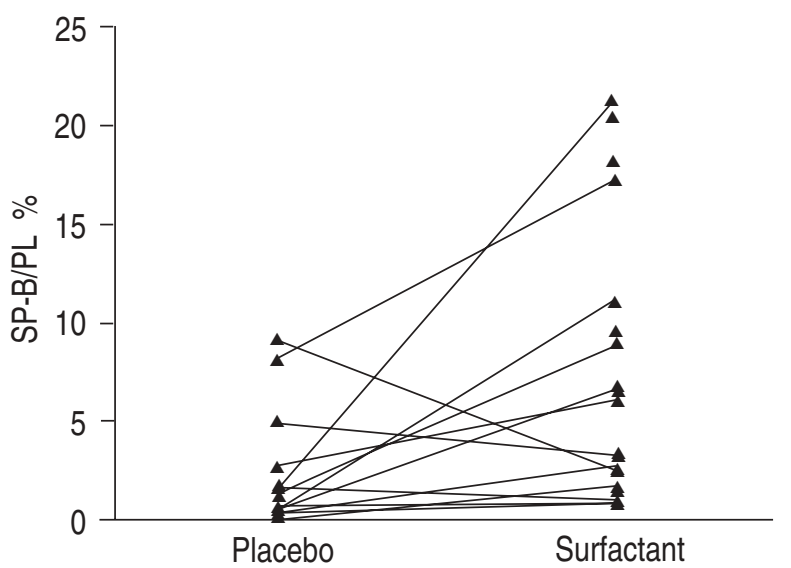

Fig. 2. - Surfactant protein-B (SP-B) recovered in sputum from five patients with cystic fibrosis was expressed as a percentage of nonchanging phospholipid (PL) mass. Values for individual subjects are connected by lines. During surfactant treatment, significantly more SP-B was recovered $(\mathrm{p}<0.001)$.
We first investigated whether the jet nebulization of the lipid-extracted, natural surfactant preparation was feasible. Although a small increase in the content of lysophosphatidylcholine was noted after nebulization to dryness, the functional activity of the material was not impaired as suggested from experiments performed in the pulsating bubble surfactometer. This was in contrast to sonication by ultrasound, which led to a loss of biophysical activity [27]. Seventy five per cent of the particles were in a range which allowed them to be inhaled into the alveolar space. Delivery was only during inspiration, and an optimized surfactant concentration allowed the inhalation of the maximum amounts. However, intrapulmonary delivery was not directly assessed with a radiotracer, because this particular inhalation device has already been shown to result in about $19 \%$ intrapulmonary delivery in normal persons [28]. In adults with $\mathrm{CF}$, a similar total pulmonary deposition is expected, the distribution, however, being uneven with a decreased aerosol entry to poorly ventilated regions [29].

Our hypothesis on the beneficial effects of aerolized exogenous surfactant in $\mathrm{CF}$ was based on a substantial amount of in vitro and in vivo data, as summarized in the introduction. The results of this pilot study clearly demonstrate no significant acute or short-term effect in these patients. The conditions used were optimized to deliver the maximum surfactant by the current state-ofthe-art jet nebulization technology.

Potential reasons for our failure to detect the expected effect on lung function include the following. Firstly, the inadequate delivery of the aerosol. This possibility, however, can be ruled out because measurements of the surfactant aerosol generated demonstrate that the majority of the particles produced were in the respirable range. Various other studies, e.g. on inhaled antibiotics or radiolabelled drugs, have clearly demonstrated intrapulmonary delivery of reasonable amounts of these aerosols.

Secondly, the distribution of the drug was inhomogeneous. This is very likely $[11,29]$. However, surfactant would have been expected to be deposited in relatively well-ventilated areas, to stabilize those airways which are patent only with the help of somewhat forced respirations, and thus improve FEV 1 and FVC.

Thirdly, the dose of the surfactant administered may have been too small. Significant improvements in FEV1 and FVC were observed in acute asthma with a much smaller nebulized dose $(10 \mathrm{mg})$ than used in this study (120 mg). Recently, Оетомо et al. [16] observed no effects in asthmatic children with chronic airflow limitation when the same surfactant as that used in the present study was administered. Surfactant delivered by aerosol has been effective in animal experiments with severe ARDS $[10,11]$. Although the amounts were some orders of magnitude smaller than those given by bolus, they were still somewhat higher than those used in human studies, when expressed per kilogram body weight (BW). In rabbits, about $4.9 \mathrm{mg} \cdot \mathrm{kg} \mathrm{BW}^{-1}$ delivered by aerosol was superior to the $100 \mathrm{mg} \cdot \mathrm{kg} \mathrm{BW}-1$ delivered by bolus [11]. Similarly, $2 \mathrm{mg} \cdot \mathrm{kg} \mathrm{BW}^{-1}$, significantly improved lung function in premature lambs with respiratory distress syndrome [30]. We estimated the delivery to the 
lungs in the present study to be in the range of $0.1-0.3$ $\mathrm{mg} \cdot \mathrm{kg} \mathrm{BW}-1$.

A fourth potential explanation as to why there was no effect on the lung function might involve the inhibition of the exogenous surfactant by inactivators, which might be present in the lung lavages of patients with $\mathrm{CF}$. This cannot be excluded, but appears less likely, as in preliminary experiments we did not find increased inhibitory activity in the protein fraction of CF bronchoalveolar lavages compared to controls (own unpublished observations). In addition, the surfactant used was a preparation with a high resistance to inhibition, possibly due to its relatively high content of SP-B [7] when compared to other lipid-extracted surfactant preparations available for clinical usage. All currently available preparations lack SP-A, which might substantially improve the quality of the surfactant with respect to low surface tension and resistance to inhibition.

Fifthly, the case could be argued that we had set too high an improvement of lung function as being clinically relevant. However, we felt that a consistent difference in FEV 1 between placebo and surfactant treatment of about $15 \%$ would be adequate, comparable to what may be expected with $\beta$-agonists. The power of the present study is high, the chance of not detecting the difference being only $10 \%$. Considering the case that only an improvement is of relevance, the power of such a one-sided hypothesis would be even greater. Lowering this power to $80 \%$ at the same sample size would be sufficient to detect $12 \%$ differences. To find smaller differences, the sample size would have to be increased.

Finally, the hypothesized relative surfactant deficiency in the small airways of patients with CF might be of no relevance for the clinical conditions observed, including overinflation, decreased expiratory flows or reduced FEV1. Although the above-mentioned studies on the pathophysiology of the small airway closure and the demonstration of impaired surfactant in CF patients argue for a role of surfactant in maintaining the patency of the airways, this hypothesis has not yet been verified. Possibly, this may be easier in younger patients with $\mathrm{CF}$, who have less severe lung injury. Further studies are needed to define more clearly the reasons for the result obtained in this trial.

The current investigation did not address other potential targets of surfactant therapy in CF. These include an improvement of surface and transport properties of CF mucus [31], and an enhancement of bronchotracheal mucociliary clearance [32]. In this study, no changes in the amount of sputum recovered were observed. Finally, pulmonary surfactant participates in the nonspecific firstline host defence reactions and may modulate the function of immune cells in the lungs [33].

Our pilot study, under the conditions of maximal surfactant administration in a realistic setting, clearly shows that nebulization of $120 \mathrm{mg}$ surfactant during inspiration does not alter forced expiratory volume in one second and forced vital capacity in adult patients with cystic fibrosis. Furthermore, daily delivery for five consecutive days did not improve lung function. Potential reasons for this failure include: insufficient amount of surfactant delivered; inhomogeneous distribution; or an inhibition of exogenous surfactant in the lungs of patients with cystic fibrosis. Thus, future studies with greater tech- nological capacities may achieve a substantially higher lung delivery, and the use of a superior surfactant preparation, possibly containing recombinant surfactant protein A, may improve lung function in cystic fibrosis.

\begin{abstract}
Acknowledgements: The authors would like to thank W. Seeger, (Gießen, Germany) and Y. Suzuki (Koyota, Japan) for the gift of the human SP-B and anti-SPB, and M. Knoche and E. Wunderlich (Pari, Starnberg, Germany) for the gift of the IS-2 nebulizer and the respiratory cycle machine. Alveofact was generously supplied by Thomae (Biberach, Germany). The authors would also like to thank P. Bartmann (Bonn, Germany) for checking serum samples for the presence of antibodies against the hydrophobic surfactant proteins. The technical assistance of A. Schams is appreciated. The computer program "fastbubs" was a gift from D. Bjarneson and F. Possmayer (Dept of Obstetrics and Gynecology, University of Western Ontario, Canada).
\end{abstract}

\section{References}

1. Halliday HL. Overview of clinical trials comparing natural and synthetic surfactants. Biol Neonate 1995; 67 (Suppl. 1): 32-47.

2. Walmrath D, Gunther A, Ghofrani HA, et al. Bronchoscopic surfactant administration in patients with severe adult respiratory distress syndrome and sepsis. Am J Respir Crit Care Med 1996; 154: 54-62.

3. Macklem PT, Proctor DF, Hogg JC. The stability of peripheral airways. Respir Physiol 1970; 8: 191-203.

4. Liu ML, Wang EL, Enhorning G. Pulmonary surfactant will secure free airflow through a narrow tube. $J$ Appl Physiol 1991; 71: 742-748.

5. Enhorning G, Holm BA. Disruption of pulmonary surfactant's ability to maintain openness of a narrow tube. J Appl Physiol 1993; 74: 2922-2927.

6. Enhorning G, Duffy LC, Welliver RC. Pulmonary surfactant maintains patency of conducting airways in the rat. Am J Respir Crit Care Med 1995; 151: 554-556.

7. Seeger W, Grube C, Günther A, Schmidt R. Surfactant inhibition by plasma proteins: differential sensitivity of various surfactant preparations. Eur Respir J 1993; 6: 971-977.

8. Weatherly M, Lewandowski J, Meyer K, Zimmerman J. Functional alterations of pulmonary surfactant isolated from cystic fibrosis patients. Pediatr Pulmonol 1991; 18 (Suppl. 6): 272-273.

9. Demirsoy A, Griese M, Birrer P, Schams A, Schürmann A, Reinhardt D. Bronchoalveoläres Surfactant bei Cystischer Fibrose (CF). Monatsschr Kinderheilkd 1996; 144: 341, P3.

10. Lewis JF, McCaig L. Aerosolized versus instilled exogenous surfactant in a nonuniform pattern of lung injury. Am Rev Respir Dis 1993; 148: 1187-1193.

11. Lewis J, Ikegami M, Higuchi R, Jobe A, Absolom D. Nebulized $v s$ instilled exogenous surfactant in an adult lung injury model. J Appl Physiol 1991; 71: 1270-1276.

12. KurashimaK, Ogawa H,FujimuraK, Matsuda T, Kobayashi T. A pilot study of surfactant inhalation for the treatment of asthmatic attack. J Allergol 1991; 2: 160-163.

13. Gregory TJ, Gadek JE, Weiland JE, et al. Survanta supplementation in patients with acute respiratory distress syndrome (ARDS). Am J Respir Crit Care Med 1994; 149: A567. 
14. DoCampo JL, Turchetto E, Bertranou EG, Hager AA, De Paoli T. Natural surfactant aerolisation in adult respiratory distress syndrome. Lancet 1994; 344: 413414.

15. Anzueto A, Baughman RP, Guntupalli KK, et al. Aerosolized surfactant in adults with sepsis-induced acute respiratory distress syndrome. N Engl J Med 1996; 334: 1417-1421.

16. Oetomo SB, Dorrepaal C, Bos H, et al. Surfactant nebulization does not alter airflow obstruction and bronchial responsiveness to histamine in asthmatic children. $\mathrm{Am}$ J Respir Crit Care Med 1996; 153: 1148-1152.

17. Gortner L, Bartmann P, Pohlandt F, Bernsau U, Porz F. Early treatment of respiratory distress syndrome with bovine surfactant in very small preterm infants: a multicenter controlled clinical trial. Pediatr Pulmonol 1992; 14: 4-9.

18. Suzuki Y, Kogishi K, Fujita Y, Kina T, Nishikawa S. A monoclonal antibody to the 15,000 Dalton protein associated with porcine pulmonary surfactant. Exp Lung Res 1986; 11: 61-73.

19. American Thoracic Society and European Respiratory Society. Respiratory mechanics in infants: physiologic evaluation in health and disease. Am Rev Respir Dis 1993; 147: 474-496.

20. Bligh EG, Dyer WJ. A rapid method of total lipid extraction and purification. Can J Biochem Physiol 1959; 37: 911-917.

21. Folch J, Lees M, Sloane Stanley GH. A simple method for the isolation and purification of total lipids from animal tissues. J Biol Chem 1957; 226: 497-509.

22. Duck-Chong CG. A rapid sensitive method for determining phospholipid phosphorus involving digestion with magnesium nitrate. Lipids 1979; 14: 492-497.

23. Gilfillan AM, Chu AJ, Smart DA, Rooney SA. Single plate separation of lung phospholipids including desat- urated phosphatidylcholine. J Lipid Res 1983; 24: 1651-1656.

24. Krämer HJ, Schmidt R, Günther A, Becker G, Suzuki $Y$, Seeger W. ELISA technique for quantification of surfactant protein B (SP-B) in bronchoalveolar lavage fluid. Am J Respir Crit Care Med 1995; 151: 1540-1544.

25. Bartmann P, Bamberger U, Pohlandt F, Gortner L. Immunogenicity and immunomodulatory activity of bovine surfactant. Acta Paediatr Scand 1992; 81: 383-388.

26. Motulsky H. Intuitive Biostatistics. New York, Oxford, Oxford University Press, 1995.

27. Winsel K, Bergmann K, Lachmann B. Untersuchungen über die Ultraschallvernebelung von oberflächenaktiven Stoffen aus Lungengewebe und Lecithin-Dispersionen im Hinblick auf die künstliche Befilmung von Lungen. Z Erkr Atmorg 1974; 140: 151-158.

28. Hardy JG, Newman S, Knoch M. Lung deposition from four nebulizers. Respir Med 1993; 87: 461-465.

29. Alderson PO, Secker-Walker RH, Strominger DB, Markham J, Hill RL. Pulmonary deposition of aerosols in children with cystic fibrosis. J Pediatr 1974; 84: 479-484.

30. Lewis JF, Ikegami M, Jobe AH, Tabor B. Aerosolized surfactant treatment of preterm lambs. J Appl Physiol 1991; 70: 869-876.

31. Bentzmann de SG, Pierrot D, Fuchey C, Zahm JM, Morancais JL, Puchelle E. Distearoyl phosphatidylglycerol liposomes improve surface and transport properties of CF mucus. Eur Respir J 1993; 6: 1156-1161.

32. Sanctis de GT, Tomkiewicz RP, Rubin BK, Schürch S, King M. Exogenous surfactant enhances mucociliary clearance in the anaesthetized dog. Eur Respir J 1994; 7: $1616-1621$.

33. Golde van LMG. Potential role of surfactant proteins A and $\mathrm{D}$ in innate lung defence against pathogens. Biol Neonate 1995; 67: 2-17. 